\title{
Reduced claw vacuum and b-phase during low milk flow does not impact oxytocin release and milking performance
}

\author{
Anna-Lena Neuheuser, Ann-Catherine Schwinn, Olga Wellnitz, Lorenzo E. Hernández-Castellano and \\ Rupert M. Bruckmaier*
}

Veterinary Physiology, Vetsuisse Faculty, University of Bern, Switzerland

Received 20 March 2017; accepted for publication 3 August 2017; first published online 20 September 2017

\begin{abstract}
Oxytocin release, milking characteristics, and teat condition were investigated with reduced claw vacuum and pulsation settings compared to milking at regular settings with or without pre-stimulation. The reduced vacuum and pulsation settings during low milk flow are expected to protect the teat tissue before the occurrence of milk ejection at the start of milking, and at the end of milking during a potential overmilking period, i.e. at a milk flow $<200 \mathrm{~g} / \mathrm{min}$. Seven cows were machinemilked either after a $60 \mathrm{~s}$ manual pre-stimulation, or without pre-stimulation and reduced vacuum and pulsation settings, or at full vacuum and normal pulsation during the start of milking. Plasma oxytocin (OT) concentration increased similarly in response to manual pre-stimulation and to both milking with reduced, or with full vacuum and pulsation settings, however delayed by $1 \mathrm{~min}$ if the cluster was attached without pre-stimulation. In all treatments OT concentrations remained elevated throughout milking. Milk flow curves were mostly non-bimodal at milkings after manual pre-stimulation and bimodal at milkings without pre-stimulation. The main milking time was shorter and average milk flow was higher during milking after pre-stimulation, but did not differ between treatments without pre-stimulation. Milk yields and peak flow rates were not affected by treatments. Either reduced or full vacuum settings were again applied during an intended overmilking from 200 to $100 \mathrm{~g} / \mathrm{min}$ of milk flow towards the end of milk harvest. Pre-milking teat ultrasound cross sections were recorded one day before the experiment started. Post-milking ultrasound cross sections were performed at $15 \mathrm{~min}$ after each experimental milking. Teat wall thickness was increased after milking as compared to pre-milking but did not differ among treatments. In conclusion, OT release and milking performance are similar if milking is performed with pre-stimulation, or without pre-stimulation but reduced claw vacuum and b-phase during low milk flow.
\end{abstract}

Keywords: Milking, oxytocin, vacuum, pulsation, dairy cows.

In dairy cows only up to $20 \%$ of the milk is stored in the cisternal compartment of the udder and therefore immediately available for harvesting (Bruckmaier \& Hilger, 2001). The major amount of milk is stored in the alveolar tissue and is only available for milk removal after it is shifted into the cisternal compartment through milk ejection in response to oxytocin (OT) release (Bruckmaier \& Blum, 1998). Milk ejection is triggered by tactile teat stimulation, which can be manual pre-stimulation or the liner movement of the teat cup (Bruckmaier \& Blum, 1996). During machine milking, the continuous application of vacuum to the teat requires the avoidance of transient milking on empty teats

\footnotetext{
*For correspondence; e-mail: rupert.bruckmaier@vetsuisse.unibe.ch
}

to prevent 'climbing' of the teat cup (movement upwards over the teat) shortly after the start of milking. Usually, a pre-stimulation is recommended to induce OT release and milk ejection before the start of milking to make sure that the alveolar milk is available before the cisternal fraction is removed (Weiss \& Bruckmaier, 2005; Watters et al. 2015). Thus, an interruption of milk flow between the removal of cisternal milk and the occurrence of alveolar milk can be avoided. Instead of pre-stimulation, alternative milking settings can be considered to prevent climbing of the teat cup before the availability of alveolar milk. Such a system may reduce the claw vacuum during periods of low milk flow and simultaneously reduce the liner-open phase of the pulsation cycle as well as the pulsation rate. However, the stimulatory effect of the liner movement to induce milk ejection must be sufficient also in such 
reduced pulsation settings. We have therefore tested the hypothesis that a reduced vacuum level at the teat end, combined with longer liner-closed and shorter liner-open periods of the pulsation cycle (via shortened b-phase and prolonged d-phase) during low milk flow enables milking without pre-stimulation. We have investigated the OT release, milking characteristics, and post-milking teat condition with the reduced vacuum and pulsation settings in comparison to milking with or without pre-stimulation at full vacuum and normal pulsation at the start of milking. In addition, the reduced vacuum settings were applied during overmilking at the end of milking.

\section{Materials and methods}

\section{Animals and milkings}

Seven Holstein dairy cows from the herd of the Institute for Livestock Sciences, Research Station Agroscope in Posieux (herd size 80 lactating cows, average milk production $8300 \mathrm{~kg}$ in $305 \mathrm{~d}$ ) were used in the current study. In this study, animals were in their first (2), second (2), third (2) and fourth (1) lactation, and between 200 and 441 DIM. Cows were fed ad libitum with a partial mixed ration (grass- and corn-silage, hay, soy grist) and received concentrate according to the animal's individual production level provided by automatic feeders. Experimental milkings were performed in a tie stall with a portable bucket milker (DelPro MU450, DeLaval, Tumba, Sweden). The installation of the milking system on a height of $1.1 \mathrm{~m}$ represented a midline milking system and imitated the conditions as frequently installed in modern milking parlours. System vacuum was $42 \mathrm{kPa}$ and the pulsation rate was $60 \mathrm{cycles} /$ min with a $60: 40$ pulsation ratio during the main milking phase. Milkings were performed with a standard milking unit with a top flow claw (Cluster Harmony, weight: $1.6 \mathrm{~kg}$, claw volume: $360 \mathrm{ml}$, DeLaval, Tumba, Sweden) and standard liners (liner $20 \mathrm{M}$ - LS, product number: 99900982, diameter of mouthpiece: $20 \mathrm{~mm}$, touch point pressure difference: $12 \mathrm{kPa}$, DeLaval, Tumba, Sweden). The milking system included automatically switchable settings (according to the operating instructions) of reduced claw (33 kPa) and pulsation chamber vacuum (PCV; $39 \pm$ $3 \mathrm{kPa})$, pulsation rate $(50 \mathrm{cycles} / \mathrm{min})$, and pulsation ratio $(30: 70)$, which were active during low milk flow at the start of milking $(<300 \mathrm{~g} / \mathrm{min})$ and at the end of milking (as soon as milk flow dropped below $200 \mathrm{~g} / \mathrm{min}$ ). For certain treatments the automated changes of vacuum and the pulsation settings were manually switched off.

\section{Experimental design}

Two days before the start of the experiment cows were transferred to the experimental tie stall barn for adaptation to the milking conditions. One day before the start of the experiment, an indwelling catheter (Intranule, length $105 \mathrm{~mm}$, $13 \mathrm{G}$, Vygon, Ecouen, France) was inserted into the right jugular vein. Experimental milkings were performed twice daily (04:30 am and 04:30 pm). Three different treatments at the start of milking were combined with two different treatments at the end of milking, resulting in six different treatment combinations. Manual pre-stimulation (ManSti) lasted, when applied, for $60 \mathrm{~s}$ and consisted of teat cleaning with a wet single-use-paper followed by teat and udder massage. In treatments without pre-stimulation, milking was either started with reduced vacuum and pulsation settings (RedVac) or with full vacuum and normal pulsation (NorVac). The treatments with either reduced or normal vacuum and pulsation settings (RedVac, NorVac) were again applied during a controlled overmilking phase at the end of milking, i.e. when milk flow decreased $<200 \mathrm{~g} / \mathrm{min}$, and the cluster was removed at a milk flow of $100 \mathrm{~g} / \mathrm{min}$. Thus, the resulting six treatment combinations were two with ManSti with either RedVac or NorVac (ManSti/RedVac and ManSti/NorVac) and four treatments without ManSti: RedVac/RedVac, RedVac/NorVac, NorVac/RedVac and NorVac/NorVac (Table 1). The seven experimental cows were randomly enrolled to all treatment combinations in a crossover-design over $6 \mathrm{~d}$. Every treatment combination was applied at two successive milkings on each cow (morning and evening milkings of the same day, respectively).

\section{Vacuum patterns}

To verify the applied vacuum and pulsation settings of the used milking system, vacuum recordings were performed during one evening milking. Both the pulsation chamber and claw vacuum were measured through pressure probes (pressure probe MPX5100DP, Freescale Halbleiter Deutschland $\mathrm{GmbH}$, Munich, Germany) in both pulsation tubes and one short milk tube, respectively. The vacuum levels were recorded at $0.001 \mathrm{~s}$ intervals in a period of $5 \mathrm{~s}$ around the up switch from RedVac to NorVac during milking. This data was analysed using the LabView Software 8.6 (National Instruments, Kista, Sweden).

\section{Blood sampling and oxytocin measurements}

Blood samples $(10 \mathrm{ml})$ were collected from the jugular catheter at $-2,-1$ (start of ManSti if applied), $-0 \cdot 5,0$ (immediately before cluster attachment in all treatments), 0.5, 1, $1 \cdot 5,2,3,4$ and $5 \mathrm{~min}$ relative to the cluster attachment and the start of milking, and were placed into tubes containing 3 K-EDTA. Blood samples were put on wet ice until centrifugation at $2500 \mathrm{~g}$ for $20 \mathrm{~min}$ and the obtained plasma was stored at $-20{ }^{\circ} \mathrm{C}$ until analysis. Plasma OT concentration was determined by radioimmunoassay after extraction with Sep-Pak ${ }^{\circledR} \mathrm{C} 18$ cartridges (Waters, Dublin, Ireland) as described by Schams (1983).

\section{Milk flow recording and evaluation of milking characteristics}

Milk flow was recorded with a mobile recording unit (Lactocorder, WMB-AG, Balgach, Switzerland) and the 

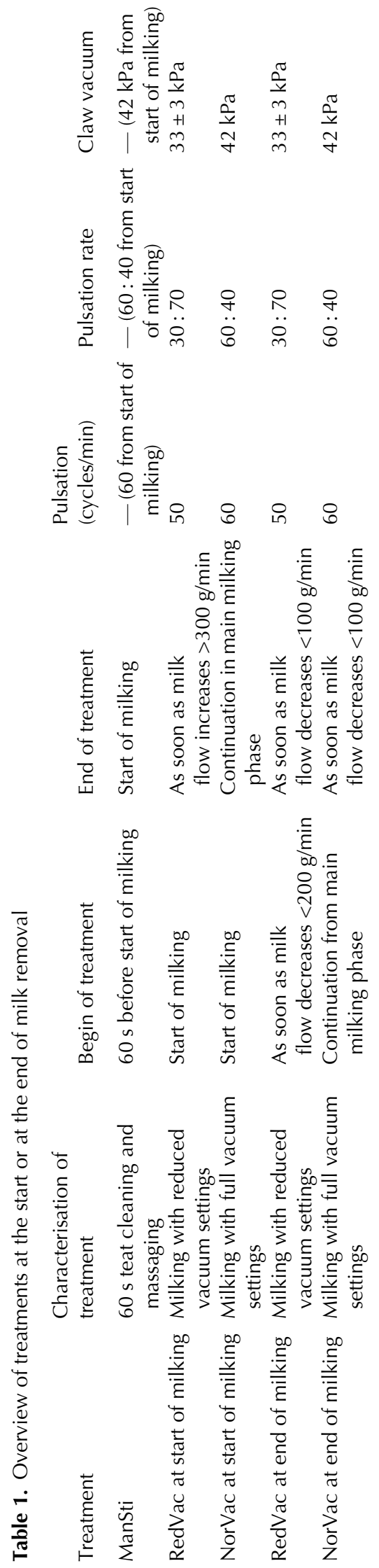

milking characteristics resulting from the milk flow profiles were analysed with the LactoPro Software (Version 5.2.0 Beta 49 software, WMB-AG, Balgach, Switzerland). Evaluated milking characteristics were total milk yield (TMY), main milking time (MMT; time from cluster attachment until milk flow decreased $<200 \mathrm{~g} / \mathrm{min}$ at the end of milking), and peak flow rate (PFR; highest milk flow maintained for at least $22 \mathrm{~s}$ ). Bimodality of milk flow was used to describe a partially separate removal of cisternal and alveolar milk. It was characterised as a transient milk flow decline of more than $200 \mathrm{~g} / \mathrm{min}$, which occurred in the period of $95 \mathrm{~s}$ after milk flow first increased above $500 \mathrm{~g} / \mathrm{min}$.

To define bimodality more precisely, the first peak of milk flow in bimodal curves, the time until the first peak of milk flow in bimodal curves, the milk flow at start of main milk flow and the time until start of main milk flow were evaluated manually according to milk flow and electrical conductivity (EC) curves provided by the Lactocorder. The occurrence of the alveolar milk ejection was characterised as the time point of milk flow increase concomitantly with an abrupt drop of EC in the harvested milk. This method is based on the fact that the first ejected alveolar milk has a low electrical conductivity (Bruckmaier et al. 2004).

Time points of up and down switches between RedVac and NorVac as well as an experimentally intended overmilking (OM; time from the milk flow decrease $<200 \mathrm{~g} /$ min until cluster detachment at a milk flow of $100 \mathrm{~g} / \mathrm{min}$ ) were recorded with a stopwatch.

\section{Teat ultrasound imaging}

Longitudinal and transversal cross section images through the right front teat were performed by B-mode ultrasonography (Draminski 4Vet Ultrasound, Olsztyn, Poland). In order to avoid any stimulatory effect on the udder and wet teats, the pre-milking teat ultrasound imaging was performed one day before the experiment started (pre-milking) as described previously (Bruckmaier \& Blum, 1992; Weiss et al. 2004). Another teat ultrasound was performed $15 \mathrm{~min}$ after the end of each milking during the trial. The teat was dipped in a cup filled with warm water $\left(37^{\circ} \mathrm{C}\right)$ and a $5-\mathrm{MHz}$ linear probe was applied from the outside of the cup using contact gel between cup wall and probe. Images were evaluated by measuring the teat wall thickness at $2 \mathrm{~cm}$ above the teat tip.

\section{Statistical analysis}

Results are presented as means \pm SEM. For statistical evaluation the MIXED procedure of SAS was used (SAS 9.4; SAS Institute Inc., Cary, NC). Milking characteristics resulting from treatment combinations were sorted after the applied treatments at the start (ManSti, RedVac, NorVac) or at the end (RedVac, NorVac) of milk removal. For milking characteristics the treatments were set as fixed effects and the animal as repeated subject. For the evaluation of OT profiles the model included treatment, experimental period (from -2 to 5 min after the start 


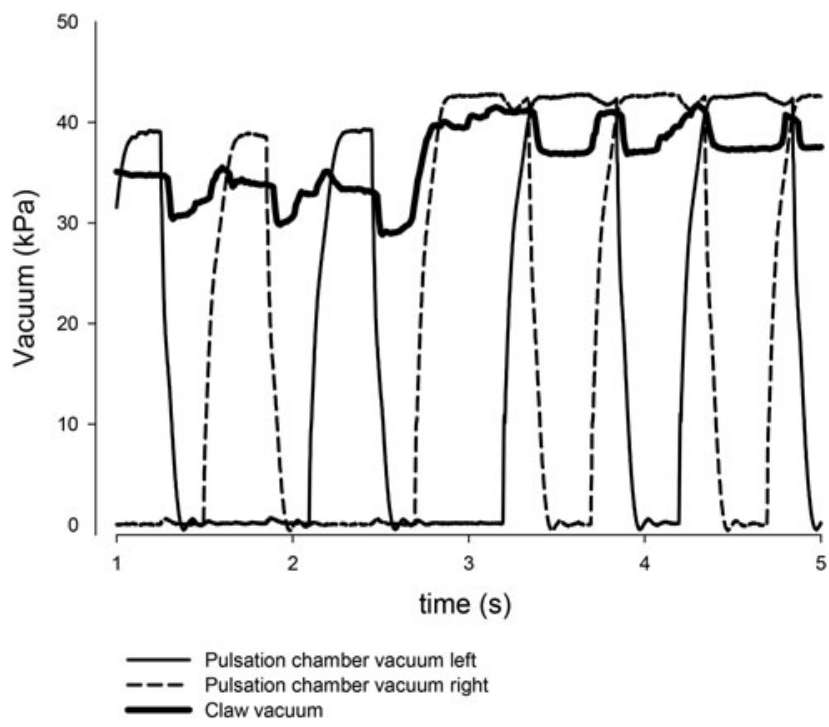

Fig. 1. Vacuum curves measured in two alternate acting short pulse tubes and one short milk tube with focus on the up-switch from reduced to full vacuum settings.

of milking) and the interaction between both as fixed effects and the animal as repeated subject. For the evaluation of teat wall thickness the model included treatment, experimental period (pre-milking and 15 min after the end of milking), and the interaction between both as fixed effects and the animal as repeated subject. Significant treatment effects were localised by Tukey's multiple comparison $t$-test $(P<0 \cdot 05)$.

\section{Results}

\section{Vacuum conditions}

The vacuum settings shortly before, during and after the upswitch from RedVac to NorVac at a milk flow of $300 \mathrm{~g} / \mathrm{min}$ were verified by simultaneous vacuum measurements in the pulsation tubes and in one short milk tube (Fig. 1). Pulsation chamber and claw vacuums were reduced during the RedVac period as planned (average claw vacuum under $\operatorname{RedVac}=33 \mathrm{kPa}$; pulsation chamber vacuum $P C V=39 \mathrm{kPa}$ ). After the switch from RedVac to NorVac the PCV was $42 \mathrm{kPa}$ and the claw vacuum immediately after the switch was $39 \mathrm{kPa}$. In both settings the claw vacuum followed vacuum fluctuations due to the actual milk flow. The measured pulsation ratio was 30:70 during the RedVac settings, and 60:40 during the NorVac settings. The pulsation rate during RedVac and NorVac was as expected (RedVac $=50$ cycles $/ \mathrm{min}$; NorVac $=60 \mathrm{cycles} / \mathrm{min}$, respectively).

\section{Oxytocin profiles}

The pre-milking baseline OT concentrations were similarly low for all treatments (Figs. 2 \& 3). Oxytocin increased within 0.5 min during manual pre-stimulation in treatment

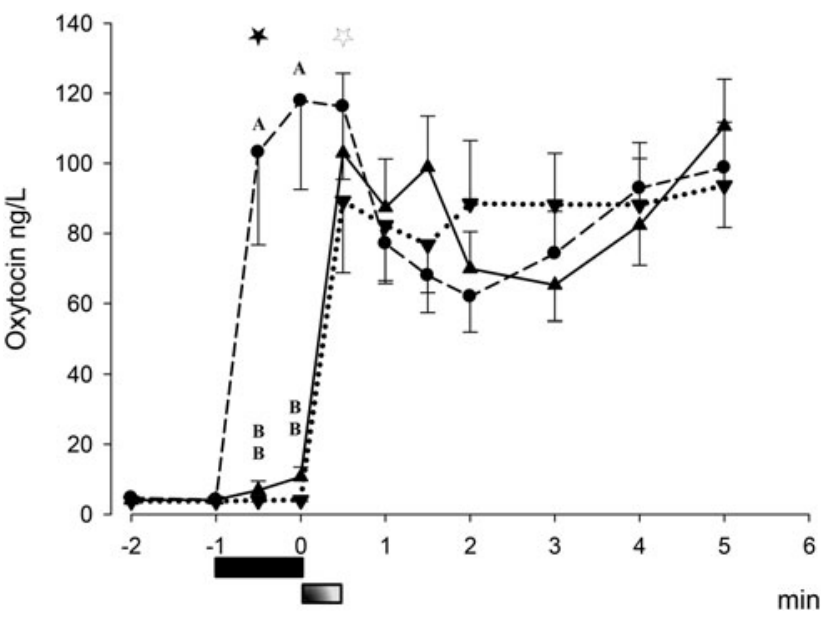

Fig. 2. Oxytocin (OT) concentrations in plasma (means \pm SEM for $n$ $=84$ milkings) from -2 to 5 min relative to the start of milking. $-\bullet-$,

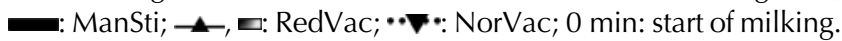
* time point at which OT means caused by ManSti are significantly elevated from baseline $(P<0.05)$ until the end of milking; $\$$, time point at which OT means caused by RedVac or NorVac are significantly elevated from baseline $(P<0.05)$ until the end of milking. $A, B=$ means without common superscription letters are not significantly different from each other.

ManSti $(P<0.05)$ and remained elevated until 5 min after the start of milking. Oxytocin concentrations remained at a basal level in RedVac and NorVac at the start of milking. In those treatments OT concentrations were increased at $0.5 \mathrm{~min}$ after teat cup attachment and remained elevated throughout milking. No statistical differences between treatments (ManSti, RedVac, NorVac) were detected for OT concentrations from $0 \cdot 5$ to 5 min after the start of milking.

\section{Milking characteristics}

Treatments: ManSti, RedVac, and NorVac at start of milking. Total milk yield did not differ between treatments $(P>0 \cdot 05)$. In ManSti the MMT was shorter $(P<0 \cdot 05)$ than in RedVac and NorVac, respectively, whereas these parameters did not significantly differ between RedVac and NorVac (Table 2). Adding the time of 1 min manual prestimulation to the MMT in ManSti leads to similar values in all three treatments. No significant differences between treatments were detected for PFR $(P>0 \cdot 05)$.

In ManSti bimodal milk flow curves occurred in $11 \%$, whereas in RedVac and NorVac bimodal milk flow curves occurred quite similarly in 79 and $82 \%$ of all milkings, respectively. A shape description of bimodality courses is shown in Table 3. During the first peak of milk flow in the bimodal milk flow curves, milk in NorVac was harvested in a shorter time compared to RedVac $(P<0 \cdot 05)$. The maximal milk flow during the first peak in bimodal milk flow curves, and the time until start of main milk flow (second milk flow increase) did not differ between RedVac and NorVac. 

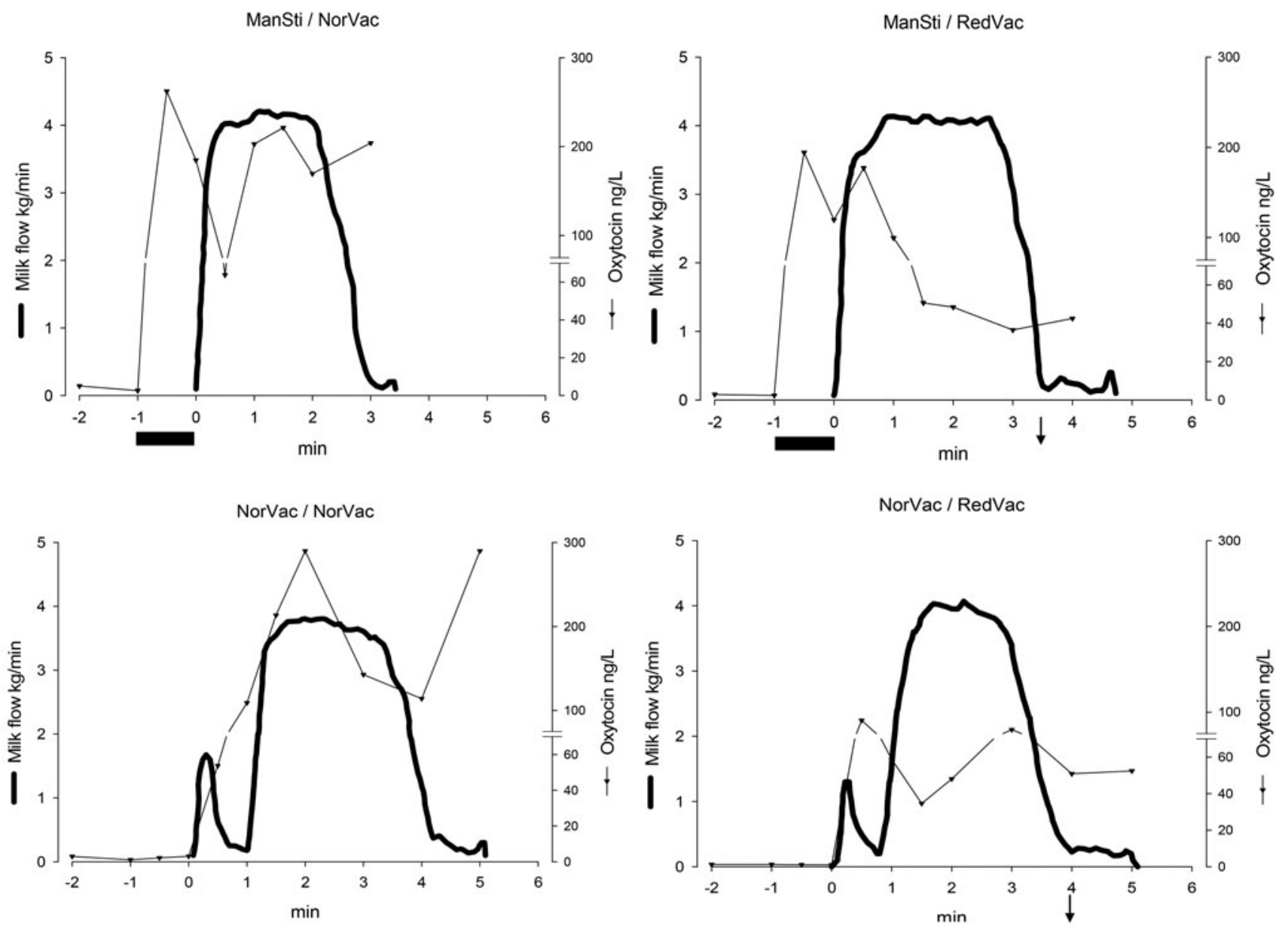

RedVac/NorVac
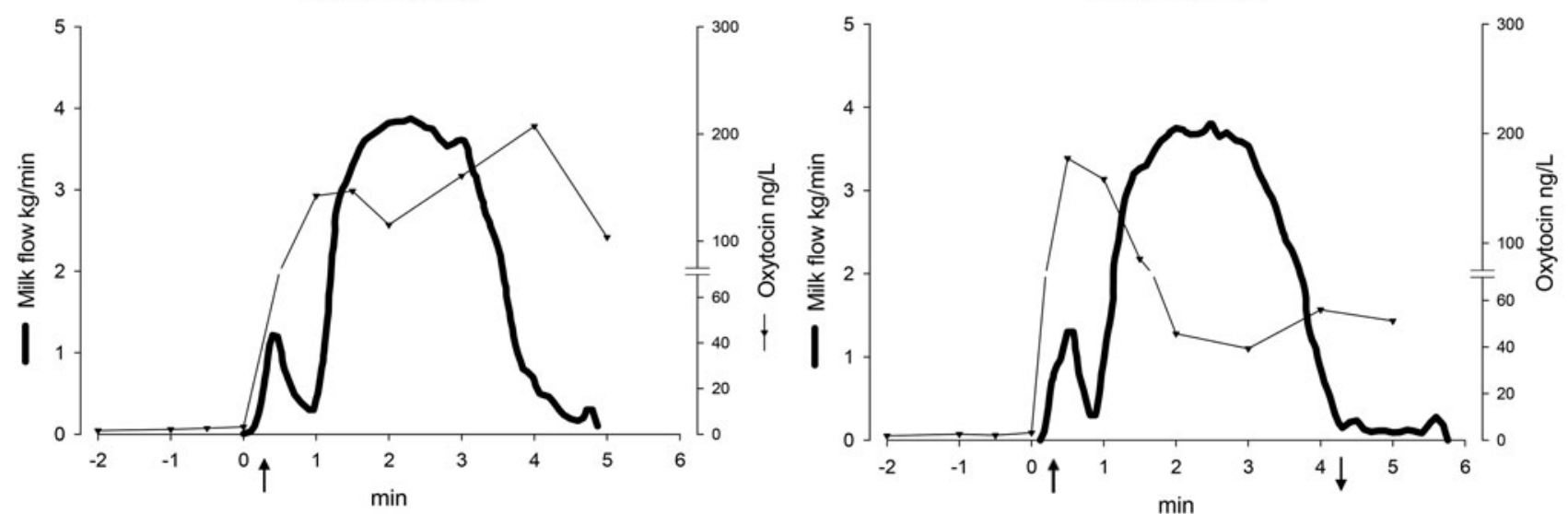

Fig. 3. Representative milk flow curves and OT concentrations in one individual cow (1891) during six different treatment combinations. ManSti, manual pre-stimulation; RedVac, milking with reduced vacuum settings; NorVac, milking with full vacuum settings; $\mathbf{Z}$, ManSti; $\uparrow$, up-switch from RedVac to full vacuum settings; $\downarrow$, down-switch from full vacuum settings to RedVac.

The first up switch from RedVac to NorVac took place within the first 0.5 min of milking (Table 4). In nine of the twenty-eight milkings in RedVac the milk flow during early milking dropped below $200 \mathrm{~g} / \mathrm{min}$ shortly after switching up to full vacuum settings and the milking machine switched back down to RedVac, before a second switch up occurred at the start of main milk flow.

No statistically significant interaction between the treatment differences at the start of milking and the end of milking was found. Consequently, we have compared the 
Table 2. Mean milking characteristics resulting from the three different treatments at start of milk removal (ManSti, RedVac, NorVac). In the assorting the end of milking is not considered

$\begin{array}{llll}\text { Variable } & \text { ManSti } & \text { RedVac } & \text { NorVac } \\ \text { TMY (kg) } & 9 \cdot 14 \pm 0 \cdot 33 & 9 \cdot 07 \pm 0 \cdot 46 & 9 \cdot 44 \pm 0 \cdot 32 \\ \text { MMT (min) } & 3 \cdot 80 \pm 0 \cdot 17^{\mathrm{B}} & 4 \cdot 96 \pm 0 \cdot 21^{\mathrm{A}} & 4 \cdot 77 \pm 0 \cdot 17^{\mathrm{A}} \\ \text { PFR (kg/min) } & 3 \cdot 69 \pm 0 \cdot 12 & 3 \cdot 52 \pm 0 \cdot 14 & 3 \cdot 60 \pm 0 \cdot 11\end{array}$

ManSti, manual pre-stimulation; RedVac, reduced vacuum settings at start of milk removal; NorVac, full vacuum settings at start of milk removal; TMY, total milk yield; MMT, main milking time; PFR, peak flow rate.

$\mathrm{A}, \mathrm{B}$ Means with different superscripts indicate significant differences between treatments $(P<0 \cdot 05)$.

two different settings at the end of milking independently of the treatment at the start of milking. At the end of milking the RedVac and NorVac settings were identical until a milk flow of $200 \mathrm{~g} / \mathrm{min}$. The period after this level is considered as overmilking because the cluster is usually removed at the latest at $200 \mathrm{~g} / \mathrm{min}$. The OM until a milk flow of $100 \mathrm{~g} / \mathrm{min}$ was significantly $(P<0.05)$ prolonged in RedVac as compared to NorVac $(1.07 \pm 0.10 ; 0.76 \pm 0.06 \mathrm{~min}$, respectively). This course of prolonged OM is also visible by the example milk flow curves of one individual cow representing all treatments (Fig. 3).

\section{Teat ultrasound imaging}

Pre-milking teat wall thickness was $7 \cdot 26 \pm 0 \cdot 25 \mathrm{~mm}$. In each treatment combination, teat wall thickness was increased at 15 min after milking $(P<0 \cdot 05)$, whereas no significant differences for individual treatment combinations were observed $(P>0 \cdot 05 ;$ ManSti/NorVac 8.25 $\pm 0.22 \mathrm{~mm}$; ManSti/RedVac $8.27 \pm 0.25 \mathrm{~mm}$; NorVac/NorVac $8 \cdot 26 \pm 0.23 \mathrm{~mm}$; NorVac/ RedVac 8.16 $\pm 0 \cdot 23 \mathrm{~mm}$; RedVac/NorVac $8 \cdot 16 \pm 0 \cdot 25 \mathrm{~mm}$; RedVac/RedVac 8.25 $\pm 0 \cdot 20 \mathrm{~mm}$ ).

\section{Discussion}

Milking machine settings are a compromise to achieve a milk removal which is fast and complete. Because the

Table 3. Shape of bimodal milk flow curves during start of milking with reduced (RedVac) or full (NorVac) vacuum load. Bimodality occurred in $79 \%$ during RedVac and in $82 \%$ during NorVac, respectively

\begin{tabular}{|c|c|c|}
\hline & RedVac & NorVac \\
\hline $\begin{array}{l}\text { First peak of milk flow in } \\
\text { bimodal curves }(\mathrm{kg} / \mathrm{min})\end{array}$ & $1 \cdot 53 \pm 0 \cdot 15$ & $1 \cdot 79 \pm 0 \cdot 13$ \\
\hline $\begin{array}{l}\text { Time until first peak of milk flow } \\
\text { in bimodal curves (min) }\end{array}$ & $0.57 \pm 0.03^{\mathrm{A}}$ & $0 \cdot 3 \pm 0 \cdot 02^{\mathrm{B}}$ \\
\hline $\begin{array}{l}\text { Milk flow at start of main milk } \\
\text { flow }(\mathrm{kg} / \mathrm{min})\end{array}$ & $0 \cdot 57 \pm 0 \cdot 12$ & $0 \cdot 55 \pm 0 \cdot 13$ \\
\hline $\begin{array}{l}\text { Time until start of main milk } \\
\text { flow }(\mathrm{min})\end{array}$ & $1 \cdot 08 \pm 0 \cdot 07$ & $0 \cdot 98 \pm 0 \cdot 05$ \\
\hline
\end{tabular}

Table 4. Switches from reduced vacuum settings (RedVac) up to full vacuum settings during the start of milking: $68 \%$ once/32\% twice $(n=28)$

$\begin{array}{llll} & \begin{array}{l}\text { Mean time } \\ (\mathrm{min})\end{array} & \begin{array}{l}\text { Minimum } \\ \text { time }\end{array} & \begin{array}{l}\text { Maximum } \\ \text { time }\end{array} \\ \text { Switch up }(n=28) & 0 \cdot 43 \pm 0 \cdot 04 & 0 \cdot 25 & 1 \cdot 25 \\ \text { Switch down }(n=9) & 1 \cdot 04 \pm 0.08 & 0 \cdot 70 & 1 \cdot 53 \\ \text { Second switch up }(n=9) & 1 \cdot 29 \pm 0.09 & 0.85 & 1.78\end{array}$

vacuum acting on the teat end changes during milking, an ideal vacuum setting for the whole milking process hardly exists (Rasmussen \& Madsen, 2000). The claw vacuum which acts on the teat during milking is responsible for removal and transportation of milk, but also for the pressure of the liner on the teat during the liner-closed phase (Mein et al. 1987). In contrast to the PCV, which is not affected by milk flow, the claw vacuum is subject to milk flow dependent vacuum losses during the course of milking which can be more or less pronounced, depending of the technical characteristics of the milking system (Ambord \& Bruckmaier, 2010; Besier \& Bruckmaier, 2016). A general increase of the system vacuum level would cause the impact of this full vacuum on the teat because vacuum drops do not occur in the absence of milk flow. This fact is of importance at the very beginning of milking and mainly towards the end of milking, when milk flow gradually ceases while the flow dependent vacuum drop disappears. It has been shown that high system vacuum increases the load on the teat tissue despite considerable milk-flow dependent vacuum drops (Besier \& Bruckmaier, 2016).

The magnitude of the OT release was quantitatively similar in the three different treatments concerning the start of milking (ManSti, RedVac, NorVac). However, the timing of the OT release occurred 1 min later in the treatments without pre-stimulation (RedVac, NorVac) as compared to a one minute manual pre-stimulation (ManSti). This observation confirms our previous findings that the normal pulsation cycle has a similar stimulatory effect as a manual stimulation (Bruckmaier \& Blum, 1996) shown by the bimodal milk flow curves observed in most of the milkings with RedVac and NorVac. The start of the second milk flow increase in bimodal curves has been demonstrated to represent the start of milk ejection (Bruckmaier \& Blum, 1996; Bruckmaier \& Hilger, 2001). Most importantly, the similarity of the OT release in RedVac and NorVac confirms our hypothesis that the OT release stimulated by the cyclic liner movement is also similar if the teat-end vacuum is reduced, the liner-closed phase prolonged and the pulsation rate reduced. We expected this result because we have previously demonstrated that the teat stimulation and its effect on milk ejection is mainly a matter of timing, and it is much less affected by the intensity of stimulation (Weiss et al. 2003). Consequently, the stimulatory effect to induce OT release and milk ejection in the reduced vacuum settings appears to be fully adequate. Even though the OT concentrations between individual milkings and individual 
animals differ, the threshold of OT to induce a maximum milk ejection (Schams et al. 1984) was certainly surmounted in all treatments and all individual milkings in the present study.

At the start of milking, an insufficient cisternal refill during the liner-closed phase concomitantly with a lack of positive pressure in the teat before the alveolar milk ejection occurs increases the probability of teat cup climbing and liner slips caused by a reduced liner adhesion (Rasmussen \& Madsen, 2000). Consequently, the risk of tissue damage is increased under those milking conditions (Nyhan, 1968; Thiel et al. 1973). From this point of view it appears to be advantageous that the bimodality in treatment RedVac had a delayed peak as compared with NorVac, while the start of the second milk flow increase in bimodal curves did not differ between the treatments. This indicates a more gentle milk removal during this period of low availability of milk in RedVac. Those findings are in agreement with other studies where the milk flow rate was affected by the system vacuum and the pulsation ratio used during milking (Bade et al. 2009; Besier \& Bruckmaier, 2016; Penry et al. 2016). However, the reduced claw vacuum and shortened liner-open phase in RedVac is supposed to prevent a pre-term climbing of the teat cup during low milk flow which would occur during the first peak of bimodal milk flow, i.e. before milk ejection. During this phase, any milk flow dependent vacuum drop is lacking which is systematically replaced by the reduced claw vacuum in RedVac (Besier \& Bruckmaier, 2016). In addition, a particularly high pressure of the liner on the teat in this treatment is avoided (Bade et al. 2009), which hence may decrease the risk of hyperkeratosis (Zecconi et al. 1992). A prolonged liner-closed phase is supposed to provide better relieve of teat congestion (Upton et al. 2016) and a slower milk removal, and therefore improves cisternal refill as long as milk ejection has not occurred, thereby also improving liner adhesion.

Not surprisingly, milk yields and peak flow rates did not differ between treatments. In ManSti the shorter MMT compared to RedVac and NorVac is expected because the pre-stimulation induced milk ejection already before cluster attachment. When the $60 \mathrm{~s}$ of pre-stimulation in ManSti are added to MMT, i.e. when milking time is calculated from the first tactile teat contact, the total milking time did not differ between treatments. This is in agreement with a number of earlier studies showing that delayed milk ejection does not necessarily result in a longer milking time (Bruckmaier \& Blum, 1996). Most importantly, this demonstrates that the reduced settings of vacuum and pulsation do not cause a prolonged milking time.

At the end of milking, reduced vacuum settings in RedVac were acting significantly longer on the teat until milk flow has decreased to $100 \mathrm{~g} / \mathrm{min}$, as compared to full vacuum settings in NorVac. This indicates again a gentle action of liner and vacuum in RedVac. Under routine milking conditions the cluster would be removed at $200 \mathrm{~g} / \mathrm{min}$ or higher. The switch to the reduced vacuum and pulsation settings at the end of milking does therefore have mainly a protective effect on the teat tissue if the cluster should not be removed in time, i.e. if overmilking occurs. As compared to pre-milking, teat wall thickness based on ultrasound cross sections was increased in each treatment combination after milking. Despite the increased overmilking time at a milk flow $<200 \mathrm{~g} / \mathrm{min}$ in RedVac, teat wall thickness did not significantly differ compared to NorVac. This means that milking with RedVac does not impact the teat condition if the cluster is not removed at the latest at $200 \mathrm{~g} / \mathrm{min}$.

In conclusion, the RedVac settings have an adequate stimulatory effect on OT release and milk ejection at the start of milking and thus help to avoid negative effects before the availability of the alveolar milk fraction on the teat tissue and further milk removal. Thus, a negative effect on the teat tissue by a potential delay of cluster removal at the end of milking due to bad milking management is likely reduced if the RedVac settings are automatically switched on when milk flow drops below $200 \mathrm{~g} / \mathrm{min}$.

The expert laboratory assistance by Mrs Yolande Zbinden is gratefully acknowledged.

\section{References}

Ambord S \& Bruckmaier RM 2010 Milk flow-dependent vacuum loss in high-line milking systems: effects on milking characteristics and teat tissue condition. Journal of Dairy Science 93 3588-3594

Bade R, Reinemann DJ, Zucali M, Ruegg PL \& Thompson PD 2009 Interactions of vacuum, b-phase duration, and liner compression on milk flow rates in dairy cows. Journal of Dairy Science 92 913-921

Besier J \& Bruckmaier RM 2016 Vacuum levels and milk-flow-dependent vacuum drops affect machine milking performance and teat condition in dairy cows. Journal of Dairy Science 99 3096-3102

Bruckmaier RM \& Blum JW 1992 B-mode ultrasonography of mammary glands of cows, goats and sheep during alpha- and beta-adrenergic agonist and oxytocin administration. Journal of Dairy Research 59 151-159

Bruckmaier RM \& Blum JW 1996 Simultaneous recording of oxytocin release, milk ejection and milk flow during milking of dairy cows with and without prestimulation. Journal of Dairy Research 63 201-208

Bruckmaier RM \& Blum JW 1998 Oxytocin release and milk removal in ruminants. Journal of Dairy Science 81 939-949

Bruckmaier RM \& Hilger M 2001 Milk ejection in dairy cows at different degrees of udder filling. Journal of Dairy Research 68 369-376

Bruckmaier RM, Weiss D, Wiedemann M, Schmitz S \& Wendl G 2004 Changes of physicochemical indicators during mastitis and the effects of milk ejection on their sensitivity. Journal of Dairy Research $\mathbf{7 1}$ 316-321

Mein GA, Williams DM \& Thiel CC 1987 Compressive load applied by the teatcup liner to the bovine teat. Journal of Dairy Research 54 327-337

Nyhan JF 1968 Effect of vacuum fluctuation on udder disease. In Paper presented at the Proceedings of the Symposium on Machine Milking 1968, Shinfield. pp. 71-82

Penry JF, Leonardi S, Upton J, Thompson PD \& Reinemann DJ 2016 Assessing liner performance using on-farm milk meters. Journal of Dairy Science 99 6609-6618.

Rasmussen MD \& Madsen NP 2000 Effects of milkline vacuum, pulsator airline vacuum, and cluster weight on milk yield, teat condition, and udder health. Journal of Dairy Science 83 77-84

Schams D 1983 Oxytocin determination by radioimmunoassay. III. Improvement to subpicogram sensitivity and application to blood levels in cyclic cattle. Acta Endocrinologica (Copenhagen) 103 180-183

Schams D, Mayer H, Prokopp A \& Worstorff H 1984 Oxytocin secretion during milking in dairy cows with regard to the variation and importance of a threshold level for milk removal. Journal of Endocrinology $102337-343$ 
Thiel CC, Cousins CL, Westgarth DR \& Neave FK 1973 The influence of some physical characteristics of milking machine on the rate of new mastitis infections. Journal of Dairy Research $\mathbf{4 0}$ 117-120

Upton J, Penry JF, Rasmussen MD, Thompson PD \& Reinemann DJ 2016 Effect of pulsation rest phase duration on teat end congestion. Journal of Dairy Science 99 3958-3965

Watters RD, Bruckmaier RM, Crawford HM, Schuring N, Schukken YH \& Galton DM 2015 The effect of manual and mechanical stimulation on oxytocin release and milking characteristics in Holstein cows milked 3 times daily. Journal of Dairy Science 98 1721-1729
Weiss D \& Bruckmaier RM 2005 Optimization of individual prestimulation in dairy cows. Journal of Dairy Science 88 137-147

Weiss D, Dzidic A \& Bruckmaier RM 2003 Effect of stimulation intensity on oxytocin release before, during and after machine milking. Journal of Dairy Research 70 349-354

Weiss D, Weinfurtner M \& Bruckmaier RM 2004 Teat anatomy and its relationship with quarter and udder milk flow characteristics in dairy cows. Journal of Dairy Science 87 3280-3289

Zecconi A, Hamann J, Bronzo V \& Ruffo G 1992 Machine-induced teat tissue reactions and infection risk in a dairy herd free from contagious mastitis pathogens. Journal of Dairy Research 59 265-271 